Portland State University

PDXScholar

5-24-2019

\title{
Equitable Academia for Students with Disabilities
}

Mia Cremer

Portland State University

Follow this and additional works at: https://pdxscholar.library.pdx.edu/honorstheses Let us know how access to this document benefits you.

\section{Recommended Citation}

Cremer, Mia, "Equitable Academia for Students with Disabilities" (2019). University Honors Theses. Paper 806.

https://doi.org/10.15760/honors.824

This Thesis is brought to you for free and open access. It has been accepted for inclusion in University Honors Theses by an authorized administrator of PDXScholar. Please contact us if we can make this document more accessible: pdxscholar@pdx.edu. 
Equitable Academia for Students with Disabilities:

A Narrative Study of Students who are Using Disability Services

An undergraduate honors thesis submitted in partial fulfillment of the

requirements for the degree of Bachelor of Arts

\author{
Mia Cremer \\ Urban Honors College \\ Psychology
}

Advisor: Jewls Griesmeyer Krentz 
STUDY OF EQUITABLE ACADEMIA FOR STUDENTS WITH DISABILITIES

\begin{abstract}
Higher education has been historically ableist based on the exclusivity of academia. This qualitative study describes how the identity of students with disabilities changes through academia. The study included semi-structured interviews with four students with disabilities who are registered with the Disability Resource Center at PSU University. Narrative inquiry revealed how the students' experience in academia revealed the infrastructure, ableism, accessibility, and classroom climate. The social model of disability provided the theoretical framework throughout the study. The social model of disability identifies how the environmental, social factors, and attitudes towards a person with an impairment prevents them from achieving equity. The implications of this study are that, through the support of Disability Resource Centers on college campuses, students with disabilities do not have to face the barriers and restraint of academic ableism alone.
\end{abstract}

Keywords: Ableism, Disability, Higher Education, Academia, Disability Services 
STUDY OF EQUITABLE ACADEMIA FOR STUDENTS WITH DISABILITIES

Equitable Academia for Students with Disabilities: A Narrative Study of Students who are

\section{Using Disability Services}

The underlying purpose of this study is to see how the world of academia addresses infrastructure, ableism, accessibility, and the classroom climate. Many higher education settings use the terms "inclusive" and "diversity" in mission statements about the integrity of the school. These words have become more and more tokenized, so much so that many marginalized populations often do not receive an equitable academic experience. The possibility for an inequitable academic experience exists due to ableism, both historic and current. This study is to explore how students with disabilities experience the ableist nature of academia and how it impacts their identity.

The scope of this topic is limited to students at Portland State University (PSU) who are registered with the Disability Resource Center (DRC). Semi-structured interviews with four DRC students gave voice to the students' stories and an opportunity to reflect on how the university resources are best serving them. Students who are registered at the $\mathrm{DRC}$ receive accommodations and use other DRC resources, such as their community space, called the DRC Safe(r) Space, and a quiet study, called the DRC Quiet(r) Space. There is not a very large disability community presence at the DRC even though this resource center interacts with a large part of the PSU student body. One of the study goals is to explore how students use the resources that are in place at the DRC. One of the advantages of the DRC is the one-on-one interactions that a student receives. Many of the people who work at the DRC are also advocates for disability rights. The social justice focus appears to add to their passion to serve the students to the best of their ability. Another advantage of the DRC is the in-house alternative formats department, which makes accessible formats of various homework, projects, and tests for its 
STUDY OF EQUITABLE ACADEMIA FOR STUDENTS WITH DISABILITIES

students. The challenge of the DRC is the amount of students that seek accommodations at the DRC. The DRC is a small resource center and they have many students registered with them. This results in a high demand for their resources and a slower production and distribution of those resources due to the limited amount of employees. Another disadvantage at the DRC is the branding of it. There are very minimal signs indicating that the DRC even exists. Making it possible for a student to continue their academic career without hearing about this university resource.

The DRC provides accommodations for students and offers a place of acceptance and inclusion. This is juxtaposed to the lack of recognition by the university. There is a paradox in having a resource center built on creating an inclusive, equitable environment for their students and a university that brands itself on inclusion but lacks distribution of a key resource for inclusion. Hearing students' voices about how they perceive their education with the accommodations allows the university to see where the improvements can be made to their perception of diversity and inclusion.

Students with disabilities who are registered with the DRC have to approach academia differently from students who are not disabled. Students with disabilities have to identify student services on campus, contact service providers and request accommodations, have documentation to receive the accommodations, and have faculty and teachers who work to provide these accommodations (Getzel \& Thoma, 2008). This study highlights the self-advocacy and selfdetermination skills that students with disabilities have to attain on their own. By hearing how these students identify, we were better able to understand how ableism, accessibility, and the classroom climate impact their academic experiences. 
STUDY OF EQUITABLE ACADEMIA FOR STUDENTS WITH DISABILITIES

\section{Review of the Related Literature}

In this study I explored how academia impacts the identity of students with disabilities in higher education. Specifically, I looked at how the students perceived their classroom climate, ableism, and their relationship with self-advocacy. The information from this study may be used to build a greater sense of community at the DRC. In many higher education settings the terms "inclusive" and "diversity" are used in mission statements about the integrity of the school. These words have become more and more tokenized to the extent that they have become meaningless. Many marginalized populations are often not getting equitable an academic experience despite the institutions' voicing their commitment to the contrary (Bialka \& Morro, 2018).

For many people, their knowledge of people with disabilities is limited to the media's portrayal of people with disabilities. The media has historically misrepresented and devalued disability issues, and this is a reflection of ableism in our society (Jones, 2012). Through the internet, people with disabilities have been able to better connect with their peers and resources. Though this is beneficial, many websites are still not accessible (Jones, 2012). In addition, many university physical structures, homework, projects, and classroom climates are not accessible. Therefore, students have to advocate for themselves to gain accommodations through their disability services offices. A non-disabled student's academic experience is inherently different from a student with disabilities, because, historically, academia was not made for the disabled. Ableism is engrained into our society. The traditional way to look at people with disabilities has been through the medical model, where the focus is primarily on the medical conditions a person may have (Lalvani \& Broderick, 2013). This is an issue, because it is not looking at a person's full abilities but rather their impairments. An ideal world would follow the principles of 
STUDY OF EQUITABLE ACADEMIA FOR STUDENTS WITH DISABILITIES

universal design, because it is not a person's disabilities that disables them, it is society and the environment (Brown \&Leigh, 2018).

The current political climate has made the demand for disability rights even more pertinent. President Trump's repeatedly uses of ableist language and derogatory terms for disability as a metaphor for weakness and failure in the United States. The danger of this is that it plays into the fear of disability (Harnish, 2017). As a society, if we continue to allow these systematic barriers to occur, people with disabilities will continue to face ableism in their daily lives (Whitman, 2018). This study gathered student perspectives that may inform how to build a greater sense of community at the DRC. The DRC may use the results of this study to gain insight into how students who are registered with the DRC are impacted by their academic environments. In doing so, this study has the potential to help give students with disabilities further support to achieve their academic goals.

\section{Positionally Statement}

My interest in studying disabled students' personal experiences in education began when I got hired to work as a classroom assistant for students with disabilities at the DRC. Being employed at the DRC, I learned about ableism for the first time and the privileges that I hold as a non-disabled person. Being a classroom assistant gave me the opportunity to connect to the disability community at the PSU. The students that I have had the privilege to work with have taught me that every student's academic experience is vastly different, but, for students with disabilities, there are more invisible barriers that limit their access to an equitable education. As a female person of color, I have taken many classes about racism and sexism, and I have also been exposed to the communities and events that connect on these issues on the PSU campus. 
STUDY OF EQUITABLE ACADEMIA FOR STUDENTS WITH DISABILITIES

Although ableism is as detrimental as racism and sexism, the DRC is one of the few spaces at PSU that students with disabilities are represented, have a dedicated community space, and are actively trying to negate ableism on campus. By being around the dedicated, passionate, and knowledgeable community of the DRC I have grown to see myself as an advocate for disability rights and an ally to the disability community. This study is important to me because I want to make a space for students with disabilities to reflect on their experiences on academia. Through hearing their stories, I hope to learn what we can do as a community to expand awareness about ableism and how we can create a much more equitable environment for students with disabilities.

\section{Methods}

Participants

I recruited students with disabilities from the DRC with the help of the Access Counselor and Consultant and the Director of the DRC. A recruitment letter was sent out in the weekly DRC newsletter, called the Wednesday Weekly. An additional recruitment email was sent out from the Director and the Access Counselor and Consultant to students who were registered with the DRC. It was critical that they assisted in this recruitment process, because I work at the DRC and it was important to the integrity of the study that I did not interview anyone with whom I worked previously. The participants received a $\$ 10$ gift card to Starbucks in compensation for their participating in the study.

After the recruitment was sent out, there was a total of 84 responses from students with disabilities who were interested in participating. This reaction to my study was overwhelming and unexpected. Due to my own resources and time restrictions, I decided to randomly reach out 
STUDY OF EQUITABLE ACADEMIA FOR STUDENTS WITH DISABILITIES

to ten participants for their availability. Each participant was numbered and through a random number generator, I was able to collect the ten random participants. I reached out to the ten prospective participants for their availability and interest level. I received responses from four participants that were interested, and two responses from participants who did not want to continue with the study. I did not have a response from the other four individuals selected. Pre-survey

Prior to the interview, I asked all four participants to complete a pre-interview survey with basic demographic questions. Participants ranged in age from $19-51$ years old. There was one male, two females and one person who identified as transgender and went by the pronouns they/them. One person was an immigrant to the United States and English was not their first language. The other three participants were born in the United States and identified English as their first language. One participant was a first-year student at PSU while the other three were in their second, fourth, and fifth year. The majors represented were Child, Youth \& Family Studies, Criminal Justice, Applied Linguistics, and Social Work.

Conceptual Framework

The social model of disability was the theoretical model used in the study. This model suggests that environmental, social factors, and attitudes towards a person with an impairment prevents them from achieving equity (Inclusion London, 2015). This model looks at separating the impairment from disability. The social model of disability views an impairment as something that makes it difficult for a person to do something. Disability is something that society has placed on a person with an impairment (Hirschmann, 2012). The social model of disability is important for this study because it comes from a social justice perspective. 
STUDY OF EQUITABLE ACADEMIA FOR STUDENTS WITH DISABILITIES

By approaching my study from a social justice framework, I was be able to analyze the how well academia addresses infrastructure, accessibility, and classroom climate for students with disabilities. It helped me to identify the patterns and behaviors that benefit or hinder student's academic experience. This framework also helped promote community building and reciprocity among marginalized populations (Inclusion London, 2015). By being critically conscious, I hope to encourage further social justice education in higher education settings.

\section{Procedure}

Going through the IRB exception process was the first step in conducting this study. Since this study included working with people in a marginalized class it was imperative that we go through the IRB process very thoroughly. This entailed drafting the recruitment that would be sent out to the students and collaborating with the Access Counselor and Consultant and the Director of the DRC. Once we gain IRB exemption, we were able to start the recruitment process.

The recruitment for this study was posted in the DRC's Wednesday Weekly. The Wednesday Weekly is a weekly newsletter that the DRC sends out to its students highlighting what's new to the DRC, upcoming events and opportunities, and resources. Recruitment was also sent out via email to a group of students with disabilities that the Access Counselor and Consultant and the Director of the DRC decided would be willing to participate and were not conflicts of interest. A day after the recruitment was sent out, the response was overwhelming. We were then able to randomly select four participants who were willing to be interviewed and participate in the study.

I interviewed two participants on Friday, May 3, 2019, and two participants on Sunday, May 5, 2019. A week prior to interviewing the participants I sent each of them a pre-interview survey. This survey had six questions that asked about their age, nationality, time enrolled at PSU, where 
STUDY OF EQUITABLE ACADEMIA FOR STUDENTS WITH DISABILITIES

they are from, their first language, and their major. All of the participants returned the preinterview survey prior to their scheduled interview. Three of the interviews occurred in a private study room at the PSU Library. The fourth interview occurred over the phone.

Each participant was given and read the informed consent that outline what was going to occur in the interview. All of the participants' interviews were around 15 minutes long. The three participants for in-person interviews acknowledged and signed their consent for the interview to be audio recorded. An audio recorder was used to record the conversation and then after each interview, the recording was uploaded to a password protected computer and the recording was then deleted from the audio recording device. One of the participants experienced some personal conflicts that resulted in them not being able to arrive at the PSU Library. Instead of an in-person interview, we completed a phone interview. The participant electronically signed the informed consent and the interview was recorded over the phone. After the interview ended the audio was uploaded to a password-protected computer and then deleted from the audio recording device.

After the audio files were uploaded to the password protected computer, I began the transcription process. This involved listening to each interview and writing exactly what the participants and I said. After the transcription was completed, I began coding the data. Through initial coding I was able to interpret the data in short and precise phrases (Thornberg \& Charmaz, 2014). From those initial codes, I then grouped them into more conceptual categories. These categories allowed me to compare them to one another and see possible relationships (Saldaña, 2016). From these categories, I was able to pick out the themes in the data and begin the data analysis. 
STUDY OF EQUITABLE ACADEMIA FOR STUDENTS WITH DISABILITIES

\section{Findings}

Coding of the four semi-structured interviews revealed four recurrent themes: community, access to services, self-advocacy, and stigma. I am defining community as a group of people that share the same interest, attitudes, and goals. Having a community can greatly impact a person's sense of belonging and affect the way that they navigate their space. Access to services is the ability to obtain resources that are either essential to an individual's ability to equitably live their life or would greatly improve a person ability to achieve their goals. Self-advocacy is the ability to advocate for oneself and what one's needs. Self-advocacy is necessary for people with disabilities to confront ableism in our everyday society. Lastly, stigma is having prejudice behaviors and attitudes against someone else. Stigma towards people with disabilities is built into the foundations of academia and can lead to ableist ideas, attitudes, and spaces.

\section{Community}

The participants spoke of the disability community repeatedly, and, although these communities intersect, they often spoke of the DRC community and the PSU community separately. The PSU community was enticing to the participants because of the public perception that people are open and able to be their true authentic selves at PSU. For example, Lauren stated, "Like, I can marry a woman, I can have an abortion, everything's fine. So I started looking at Portland, then Portland State.” This was different for Sam, who referenced her experience stating that "finding a community of support took a lot of time." The huge student body and the lack of accessible advertising to all the communities at PSU made it much more difficult for some participants to find a community that best fit them.

Another participant, Cody, referenced the feeling of not fitting into the PSU community, whether it be because of sexual orientation, gender, or disability status, and stated, "[I built] my 
STUDY OF EQUITABLE ACADEMIA FOR STUDENTS WITH DISABILITIES

own community individually, but I did not feel like I was a Portland State community member."

Finding a community willing to accept and support one openly, lead another participant, Taylor, to feel encouraged to continue to excel in her academic studies. In addition to personal support systems, the DRC community is a community built on acceptance, support, and independence. The DRC emphasizes building real relationships with their students and this leads to more successful students. Taylor said, "I think the DRC is really commendable. I think the people they have, are incredibly approachable. I think they've made safe spaces for people.”

Cody mentioned that the first thing he did when they got into PSU was "the financial aid. Second thing was the DRC." It is significant that a student found reaching out to the DRC to be one of the more important things to do when applying to PSU. I think comparing registration with the DRC with financial aid shows what a large role accessing disability services plays in a student's life and academic success.

Sam identified as transgender and went by they/them pronouns. They spoke about finding a place in the disability community at PSU and the LGBTQ+ community. They indicated, "Being trans, you kind of get grouped up with trans people." They struggled to get accommodations from University Housing allowing them to room with other transgender people and accommodate their disability. They recalled, "We're all trans, and so housing has issues with that. Not openly." After housing ignored a request for a fellow transgender roommate, they felt that it was "very stressful to live in that constant state of uncomfortableness." Sam explained that the situation led them to seek housing off campus and they stated, "I feel a disconnect from it now, being I have my own QRC [PSU's Queer Resource Center] within my family of friends that I have." 
STUDY OF EQUITABLE ACADEMIA FOR STUDENTS WITH DISABILITIES

Access to Services

Access to Services emerged from the participants' conversations around finances, accommodations from the DRC, and access to information about what is happening at PSU. All four participants discussed these three themes repeatedly. Access to financial support is a large concern for many students. For instance, Taylor found, "The first major obstacle that continues to be one, sort of, is just how to navigate financial aid and how to navigate registration. I'm a pro at it now, but when I first started, that was so hard for me." For students with disabilities, these concerns may be compounded by the cost of additional supportive resources like accessible technology, transportation, and accessible living spaces. Many participants found access to financial services difficult. For example, Lauren said it was a "very nebulous set of services that I don't really understand how they all work." This is a barrier to a student's access to financial support that has the potential to influence a student's academic success.

A commonality among the various sub themes is that many services offered at PSU are inaccessible. Thus, a student must maintain constant communication with the DRC. Services like transportation, housing, and access to information were all regarded as services that hold inaccessible systems within them. Sam found that transportation was an obstacle to getting to school, "So that's been one of the harder things, getting around." Cody put a lot of importance on being in class on time and would have to use public transportation and leave "an hour and a half to two hour ahead of time." At times he was still late and that caused him a lot of distress. There was also frustration around the high cost of transportation. Participants also referred to "transportation" as the ability to navigate around campus. Sam spoke about the challenges they faced when navigating PSU's campus. They noted difficulty "navigating everything, whether it be transportation, not being from here." Some participants indicated that access to information 
STUDY OF EQUITABLE ACADEMIA FOR STUDENTS WITH DISABILITIES

about road closures, elevator closures, and the placement of a class was difficult without the support and updates from the DRC.

When a student is registered at the DRC they are able to access accommodations that can help them with academics, housing, and technology. Accommodations are different for every student, based on the social model of disability, and modify the ways in which students are able to access academics and student life. Accommodations do not aim to change or modify the students themselves. Sam found that these modifications helped build confidence and identity. In reference to the DRC, Sam stated, "They're there to help you. They are there to guide you." Participants shared stories about the ways in which the DRC helped give them resources in the classroom environment. Cody acknowledged how accessible tables and chairs helped him and said,"I have a desk for myself. I have a chair that help me with my back." Many of the buildings at PSU are old, which means that the entrances, elevators, and classroom were originally set up for non-disabled people in academia. The DRC has made suggestions to changes to the buildings and provided accommodations when buildings are inaccessible.

Although one participant, Taylor, expressed a desire to attend some of the technology workshops and other events, they suggested having alternative options "on YouTube or something, because I can't make that time. If they did things like entice me with free childcare, maybe, sure, it could possibly, maybe, make me go to one of those things," This is an obstacle that the DRC needs to address. If they were able to offer free childcare, potentially more students would be willing to use their services.

Taylor, who is a new parent and a person with disabilities, described struggling to learn how to access the resources she needs, adding, "So, I've been trying to learn how to interface with parent services, along with disability services, and they are separate services. So, my 
STUDY OF EQUITABLE ACADEMIA FOR STUDENTS WITH DISABILITIES

success, I would actually say the note-taking has been incredibly useful because I nurse in class." Taylor acknowledge wanting assistance for, not only juggling disability accommodations, but also managing the balance of parent accommodations, like the ability to nurse in class and while still engaging. Many participants expressed not knowing how to find the resources that they needed. For instance Sam said, "I think at that point, it was just that I didn't know where to go to find the resources I needed." This is a flaw in PSU's ability to support their students. Stigma intersects into students' ability to access services, leading students to feel like they would be seen as a burden if they reached out for help. This results in students not being able to access the academic equity they deserve.

\section{Self Advocacy}

All of the participants used self advocacy when they shared their personal journeys of learning about their disabilities, seeking out support, and accommodations. Every participant spoke of the importance of building relationships with professors that involved clear communication and support of their accommodations with the DRC. Lauren suggested, "just being honest with professors all the time". Participants felt more at ease in the classroom environment when they were to use their self advocacy skills and honestly express their needs. Sam said, "I know it's important to talk to your professors, and I've been very upfront since freshman year, about here are the things that might happen. So I think I'm pretty good at seeking out, knowing that my professors know what's going on." The ability to be open about your disability in education is confronting the foundations of stigma that academia traditionally holds.

Participants described having to advocate for themselves more when professors' communication styles did not meet their needs, which directly impacts their ability to succeed in their academics. Taylor expressed her frustration when a professor was unwilling to adopt a 
STUDY OF EQUITABLE ACADEMIA FOR STUDENTS WITH DISABILITIES

communication style that would be more accessible to her. Taylor reported that one professor told her that "it was very disrespectful the way you've been sending me emails. I don't need to hear that you have all these problems." Taylor continued, "I'm like, well, look, I'm legally blind, and I have a baby, and I really needed some guidance on the last paper". This lack in effective, adaptable communication, and acceptance of Taylor, led her to feel misunderstood and labeled; she ended up switching classes because she was unable to get the support that she needed. This situation is an example of a student advocating for themselves and not being heard. The process of seeking out accommodations requires a student to advocate for themselves by requesting the help and support they need.

PSU's equal opportunity statement suggests the institution supports "equal opportunity in admissions, education, employment, housing, and use of facilities by prohibiting discrimination in those areas based on age, color, disability, marital status, national origin, race, religion or creed, sex or gender, gender identity or gender expression, sexual orientation, veteran status, or any other basis in law". However, from the participants' point of view, many of these equal opportunities are much harder to access than the university's equality statement implies. The fight for equal access these PSU students meant opposing systematic inequalities and stigmas that have always been present in academia. This opposition required strong self-advocacy skills.

\section{Stigma}

Each of the identified themes intersect with stigma because the stigmatization of disability is so normalized in most societal structures and, therefore, stigma deeply impacted the participants access to equity. Taylor said, "I don't think there's any one way to fix the giant problems that society has dealing with disabilities". Throughout the interviews the participants detailed their experiences with inaccessible materials in the classroom and classroom environments. Lauren 
STUDY OF EQUITABLE ACADEMIA FOR STUDENTS WITH DISABILITIES

said, "But it did show me that they really were not a place for people with disabilities". Having classroom activities or projects that are not accessible for each student is not academic equity. That is why the DRC is so crucial for students with disabilities because it helps bridge the inequality gap. Unfortunately, the DRC can not change everything. The participants are still navigating the complexities of gender identity, immigrant status, and the stigma of invisible disabilities in the classroom. Sam said, "I felt more or less invisible". The complexities of stigma even affected the way that Sam viewed of themself, "My thought was, I don't deserve accommodations, I'm able-bodied". Sam who has an invisible disability expressed that it took them longer to reach out to the DRC. All of these themes make up stigma, because of the inaccessible foundations that academia is based on.

Taylor, who is visually impaired, addressed a situation where a professor's language in class referenced a lot of content as "this", "that" and "those things". She found that this made it hard to interact and participate in class discussion, "it is very difficult to be collaborative when you have no idea what they just wrote up there". When a professor unknowingly uses this language, it often lead Taylor to feel isolated.

When a student receives support and acceptance from their professor they have more opportunities to find a community in the classroom and excel in their academics. The participants shared the impactful experiences they have had with professors who openly expressed their support. Cody said, "I wish that there was a prize to give to those teachers because she never complained that I email her, and I email her a lot because of my language, and because of my disability." Participants were able to find communities with which they could identify when they had supportive professors. Sam said, "I had a professor who I still have now. I've taken her classes. Try to take one a term because she's great. And it's been really nice, kind 
STUDY OF EQUITABLE ACADEMIA FOR STUDENTS WITH DISABILITIES

of getting a community in there". The positive relationships that Sam and Cody have built with some of their professors gave them support to face the other obstacles associated with being a student with disabilities.

The concept of holding enough space was continuously explored throughout the interviews. Participates shared stories of not being heard, disregarded, and not thought of in the classroom. Sam said, "So it was something where it's like it didn't feel like it was my space anymore". These are all results of stigma towards people with disabilities, even if the person engaging in the behavior is not aware of it. The importance of holding space for everyone relates to the building of communities. If students with disabilities do not feel like their classroom is a space for them, then they are less likely to be active in the academic environment and achieve academic success. When more students with disabilities achieve success, more doors open and create more spaces that are inclusive for everyone.

\section{Implications}

This study investigated how a student with disabilities' identity changed through academia. I conducted interviews with four students with disabilities who are registered at the DRC. The interviews focused on how PSU addressed infrastructure, ableism and accessibility, and the classroom climate. The interviews revealed themes of community, access to resources, self advocacy, and stigma, which all impacted the participants role as students at PSU.

Community provided participants with support, guidance, and affirmation. The participants all identified with the disability community and the DRC community at PSU. Their roles in these communities influenced their abilities to find additional communities such as the LGBTQ+ community, Urban Honors College community, and cultural communities. 
STUDY OF EQUITABLE ACADEMIA FOR STUDENTS WITH DISABILITIES

Communities are important because they provide kinship networks, meaningful social relationships, and safe spaces for students to explore their own growing identities (Chupp \& Joseph, 2010).

Access to resources, such as DRC accommodations, helped to create academic equity at PSU. However, despite these efforts, the participants expressed their experiences with inaccessible resources like, transportation, PSU websites, financial aid services, and housing. The resources that are accessible for non-disabled people are made inaccessible because of ableism in our society. The participants shared how the barriers to resources impacted their academic performance and perceptions of themselves. Through identifying with the community at the DRC, the participants have been able to use their services and become advocates for equal access education and navigate the ableism in academia.

The participants' use of self advocacy skills facilitated the ways in which they were able consume in class material, participate in their classes, and combat stigma. Through self advocacy the participants were able to demonstrate that society is disabling, not their visual, mobile, or mental impairment (Hirschmann, 2012). The classrooms, materials, and people for whom academia was exclusively built restrains students with disabilities and limits them from achieving the same amount of success as their peers. With the support of disability services like the DRC at PSU, the participants did not have to face this barriers and constraints on their education alone.

In future studies of students with disabilities on college campuses, it is important to conduct more interviews. Enlarging the participant pool in future studies, would allow for correlations to be made from the themes that are picked out through a narrative inquiry. This study could make generalizations about how universities treat students with disabilities and how 
STUDY OF EQUITABLE ACADEMIA FOR STUDENTS WITH DISABILITIES

they are being represented in higher education with more interviews. By hearing more students with disabilities experiences in academia, future studies could advocate for greater changes to be made in higher education to continue to strive for equity for every student. Universities have an obligation to all of their students to provide a learning environment that creates a path to academic success. By creating space for every student, universities will see a much more diverse and vocal student body representing their institutions. Without addressing ableism in academia, universities are neglecting to acknowledge the discrimination and barriers that are put in place that prevent students with disabilities from achieving the same success as a student who is not disabled.

\section{Limitations}

A limitation of this study is that I have an established relationship with the DRC that may have impacted my interpretation of the study. I have been employed at the DRC for 3 years. I work as a classroom assistant for students with disabilities and I work at the alternative formats department that works at converting inaccessible materials to accessible materials for our students. I am also the lead classroom assistant at the DRC, and I put on events for students and help with administrative tasks and trainings. The work that I do at the DRC has taught me about Ableism and has allowed me to hear many students with disabilities experiences at PSU. Another limitation in this study is that I am also a student at PSU and I am not registered as a student with disabilities at the DRC. My experience as a student who is non-disabled has allowed me to have privileges in academia that are not accessible to students with disabilities. The small number of participants in the study is a limitation because the findings are not generalizable to all students with disabilities at PSU. 
STUDY OF EQUITABLE ACADEMIA FOR STUDENTS WITH DISABILITIES

\section{Conclusion}

The study looked at how a student with disabilities' identity changes through academia. From the four participants that were interviewed from PSU, the themes of community, access to services, self-advocacy, and stigma all affected the students' academic identities. This study will be able to give insight into a small portion of the students with disabilities academic experiences. With this research, the DRC at PSU may gain feedback on how some of their students are excelling and what obstacles they are facing. The overwhelming response to participate in this study, reflects just how important it is for students to be able to have their voice and stories heard in academia. 


\section{References}

Banks, J. (2017). “These people are never going to stop labeling me”: Educational experiences of African American male students labeled with learning disabilities. Equity \& Excellence in Education, 50(1), 96-107. DOI: 10.1080/10665684.2016.1250235

Bialka, S., C. \& Morro, D. (2018). “It didn’t come up on my radar”: an examination of students' orientation toward disability justice in the US. Disability \& Society, 33(7), 1061-1086, DOI: 10.1080/09687599.2018.1476223

Chupp, G., M. \& Joseph, L., M. (2010). Getting the most out of service learning: maximizing student, university and community impact. Journal of Community Practice, 18(2-3), 190212, DOI: $10.1080 / 10705422.2010 .487045$

Harnish, A. (2017). Ableism and the Trump phenomenon. Disability \& Society, 32(3), 423-428, DOI: 10.1080/09687599.2017.1288684

Hirschmann, N. J. (2012). Disability as a new frontier for feminist intersectionality research. Politics \& Gender, 8(3), 396-405.

Getzel, E. E., \& Thoma, C. A. (2008). Experiences of college students with disabilities and the importance of self-determination in higher education settings. Career Development for Exceptional Individuals, 31(2), 77-84. DOI: 10.1177/0885728808317658 
STUDY OF EQUITABLE ACADEMIA FOR STUDENTS WITH DISABILITIES

Jones, C. T. (2012). An audience's guide to disability in mainstream media: A review of eth Haller's representing disability in an ableist world: Essays on mass media. Journal on Developmental Disabilities, 18(1), 101-105. Retrieved from http://stats.lib.pdx.edu/proxy.php?url=http://search.proquest.com/docview/1081620883?c $\underline{\text { countid }=13265}$

Lalvani, P.\& Broderick, A. (2013). Institutionalized ableism and the misguided "disability awareness day": transformative pedagogies for teacher education. Equity \& Excellence in Education. 46 (10),1080/10665684.2013.838484.

Inclusion London. (2015). The Social Model of Disability. Retrieved from www.inclusionlondon.org.uk/wpcontent/uploads/2015/05/FactSheets TheSoicalModel.p $\mathrm{df}$

Parsons, A. L., Reichl, A. J., \& Pedersen, C. L. (2017). Gendered ableism: Media representations and gender role beliefs' effect on perceptions of disability and sexuality. Sexuality and Disability, 35(2), 207-225. DOI :http://dx.doi.org/10.1007/s11195-016-9464-6

Portland State University. (2019). Portland State University Mission. www.pdx.edu/portland-state-university-mission.

Saldaña, J. (2016). The coding manual for qualitative researchers (3rd ed.). Los Angeles: SAGE. Retrieved from: www.sagepublications.com

Thornberg, R. \& Charmaz, K. (2014). Grounded theory and theoretical coding. In U. Flick the SAGE handbook of qualitative data analysis (153-169).

DOI: $10.4135 / 9781446282243 . n 11$ 
STUDY OF EQUITABLE ACADEMIA FOR STUDENTS WITH DISABILITIES

Whitman, R. K. (2018). Perceptions of disability, identity, agency, goal attainment, and young adult disability programs. DOI: 1952972392; 201733535-187

http://stats.lib.pdx.edu/proxy.php?url=http://search.proquest.com/docview/1952972392?a

$\underline{\text { ccountid }=13265}$ 


\section{Appendices}

\section{Appendices 1}

\section{Participant 1}

Speaker 1 :All right. So, Participant 1.

\section{Participant 1:Yes.}

Speaker 1: Why did you decide to enroll in Portland State?

Participant 1:That is not a quick, straightaway answer. I'm from California originally and I moved abroad. My dad more or less retired to Southeast Asia. I went to visit him in Cambodia and just kind of fell in love and did not feel like leaving. Culture shock is awesome and it's so nice to be somewhere different and not in the United States. I had a great time. So, I stayed for six years-

Speaker 1:Wow!

Participant 1:... yeah.

Speaker 1:That's long.

Participant 1:It is. But you know, age 19-25, you're working out a lot of stuff. I had a lot of stuff to work out. Then I went to Europe for a summer and I was dating someone at the time. We thought we were going to move to Hong Kong and we would both go to college. He also had not done any college yet, so that was sort of the plan. Then he and I broke up because good reasons. We were not good together. I kind of had in my mind that I was ready to go to school, finally. When I ended up back in Vietnam, I worked for a little while and said okay let's just go back to the United States because there's financial aid. Very important, and I need that. 
Participant 1:I started looking, because I'd been gone so long, I was no longer a resident of California so I could really go anywhere and just stay there for a year, get the residency and everything. I kind of looked at the whole country. I knew that I wanted to do linguistics so I was looking at where would be a good program. Collegeboard.com is this great website.

Speaker 1:Yes! I've used it!

Participant 1:It's built for like, 18 year olds. It's so easy to use, right? It's so userfriendly. I just limited my search to program and I think that was it. I just said anything else. There's really good programs in like, Minnesota and Michigan. I was like, that's going to be too cold for me. I love a little snow, but that much snow, I don't know if I could handle. Then I thought about, I knew a guy from Michigan at the time and he said, "You don't want to go to Michigan, they're not very liberal there. You'd run into a lot of conservative things and I think you'd have a hard time with that, especially going to college".

Participant 1:I said all right, let's re-focus this on the West Coast, and then Portland just started standing out because it's liberals and good music and good beer and good food and good coffee and people that think like me. Like, I can marry a woman, I can have an abortion, everything's fine. So I started looking at Portland, then Portland State, of course just jumps out.

Speaker 1:It sounds like you had a pretty big sense of community already, like vibrating to you in Portland. That you could identify with-

Participant 1:Yeah, I couldn't find anyone saying anything bad about it. This is all just online, right? I didn't know anybody here. I had never been here before. I was reading 
STUDY OF EQUITABLE ACADEMIA FOR STUDENTS WITH DISABILITIES

a lot of blog posts and I was Facebook stalking random people. Just finding out as much information as I can. I got really used to the PSU website way before I came.

Participant 1:The first person I talked to that kind of made it real was someone in the admissions office. He told me about the holistic review process because my grades in high school were not very good because I didn't go most of the time. Then he said, "You know, you might be interested in the Honors College. Why don't you check that out?" That's when everything just started saying this is where I'm supposed to be. Participant 1:Yeah, I think the most negative thing I remember someone saying on a blog was like, "It rains too much". Here I am in Southeast Asia, with monsoon season, going, "Oh, honey". So yeah, everything that the internet says about Portland was just like, this is where I'm supposed to be. It's interesting that you say that word, community. I didn't think about it that way, but yeah. I did feel like I would be a good fit into the Portland community.

Participant 1:Then the Portland Honors College as well. That just, I'm almost done, as I told you. Everything the Honors College has done has just been everything I could have wanted from College.

Speaker 1:Where did you find success at Portland State, or the Honors College? What would you deem success?

Participant 1:I think the Honors College, really specifically. Certain other classes, sure. I've always been academically gifted? Without like, humble brag, you know? I'm smart. My dad's like, a Harvard grad lawyer person. His whole family is incredibly intellectually gifted. Luckily I have some of those genes. I read a lot. I understand a lot, like at a first pass. I have great comprehension, great test scores. It was nice to put those 
skills to use again. I hadn't used them for so long, right? Just being a student, I was a little more successful than I think I expected myself to be. Additionally, the whole time I was living in Asia, I was a teacher. I was teaching ESL.

Speaker 1:Oh, wow. That's really interesting.

Participant 1:It was fun. I mean, I love grammar and language. It was such an easy fit. You can get a job literally anywhere if you're a white English speaking female, like I am. That's exactly what they want. They have a lot of like, old white men, so imagine a 22 year old white woman. Like, yay, right? They were stoked.

Participant 1:That was the other thing that made me successful, initially, was I know what teachers want because I was one. I know they don't care. They don't want me to lie to them about being sick. Just tell them when you're sick. Or if you're having a tough day, let them know and be a human being. Treat them like human beings and they'll treat you like one. So, I already, I think, had a different mindset than say, the average 18 year old, who has just come out of high school and doesn't know what to expect from teachers.

Speaker 1:Absolutely. So, self advocacy is something that you came into Portland State already having?

Participant 1:As a student, yes. In other ways of my life, no. But as a student, yeah. I think because I would always wish that my students would come to me and tell me what's going on instead of just flaking out or not showing up. Just being honest with professors all the time, and asking them all the questions because I know there's no such thing as a dumb question. If you don't understand something, you have to tell me. Otherwise I'm going to keep going on. 
STUDY OF EQUITABLE ACADEMIA FOR STUDENTS WITH DISABILITIES

Speaker 1:So, going on professors, what obstacles have you found by going to Portland State in regards to professors, classroom climate, the campus as a whole? Personal obstacles?

Participant 1:There's a lot. There's so many ways to answer that question. I think the first major obstacle that continues to be one, sort of, is just how to navigate financial aid and how to navigate registration. I'm a pro at it now, but when I first started, that was so hard for me.

Speaker 1:It's hard to navigate. Even on the website.

Participant 1:It's so complicated! How do you fill out your FAFSA? That's complicated. How do you make sure that you're getting enough aid? How do you make sure you're filling everything out correctly? How do you make sure you're signing up for the right classes? I think at that point, it was just that I didn't know where to go to find the resources I needed.

Participant 1:After I'd been here for a while, I knew where to go but that initial, "Oh my god, what do I do?" Especially from coming from out of the country and having not been here so long, I can only imagine how someone who English isn't their first language, I can only imagine how that would feel. It's so daunting.

Participant 1:Then I think not knowing, on the personal level, every time I tell someone I came here, I didn't know anyone, I didn't know anything, I'd never been here before, people are like, "Wow, that's really brave of you". It's like, yeah, but I love traveling alone. I love going to a new place where I don't know anything. That's fun for me. That was less of a struggle, but I think when things did get difficult, finding a community of support took a lot of time.

Speaker 1:What led you to seek accommodations from the DRC? 
Participant 1:I have what is now diagnosed as Complex PTSD. It's funny, because it sounds so ... I don't know how this sounds, cliché, maybe? Complex PTSD means there's a variety of traumas that I've just experienced in my life. Some of them when I was a kid with family drama. My mother's an alcoholic, and just stuff. Then other things when I was just living in Asia, like, I saw a man die right in front of me. I didn't know him, but that doesn't change the fact that it's trauma.

Speaker 1:That's very hard. Absolutely.

Participant 1:It's just cut and dry, this is traumatic. So, sort of the layers of different things. It's not in the DSM yet. My therapist is very upset about that. Apparently many people are. There's a whole community of people that have this diagnosis for such a wide variety of reasons.

Participant 1:When Trump was elected, my panic attacks started coming back. When I saw that guy die, that was the first panic attack I'd ever had. I was like, 28, you know? No, 27, because it was before I came to school. That was a whole new world of experience for me. Then they went away after a while, you know. It took a few months and then you kind of get through some things. Then Trump got elected and they started coming back.

Participant 1:I was just not coping well. My stress levels were through the roof. My anxiety was through the roof. I hadn't dealt with any of my stuff, right? I have a whole lifetime of stuff to deal with that I just like, numbed out for most of my $20 \mathrm{~s}$. There were a couple specific incidences of like, okay I am not okay and I need help. Participant 1:I actually went to the DRC first and I just said, "Look, I know you probably need me to go see a therapist of a mental health professional, but I just want 
to know, the kinds of things that I'm going through, is this even DRC accommodate?" I don't even know the word. "Is this something that you guys would be able to help me with?" Jewel, who is delightfulSpeaker 1:She's wonderful! Participant 1:... right? She's just so great. She's like, of course we would. It sounds like we would do these two things and one of them would be it sounds like maybe you could benefit from taking breaks in class. Like, just getting up and walking around if things get to be too much. I said, "Yes! That sounds great!" She says, "It doesn't sound like you're the kind of person that misses class a lot, based on your GPA and what you're telling me. It sounds like you really want to be here, so we could also go through these allowed absences that, obviously you would need to make up the work, but your teacher really shouldn't penalize you if you're absent if you're having a mental health day." Participant 1:Those are the two accommodations that she and I talked about and I said great. Then I went and found my therapist, who is now like, my favorite person. Speaker 1:Therapy is amazing. Changes the game.

Participant 1:It's like, why isn't everyone in therapy? Speaker 1:Right?

Participant 1:So yeah, after I had seen my therapist, I think for a month or two ... I started seeing her last July, so it was over the summer. I don't take classes in the summer, so then when fall term last year came up, I said hey, there's a form, would you fill this out so I can make these accommodations? That's how that went. 
STUDY OF EQUITABLE ACADEMIA FOR STUDENTS WITH DISABILITIES

Speaker 1:So what are some areas of improvement that the DRC could do, if you see any? Or what areas of improvement could Portland State, when it comes to students with disabilities, mental, physical, invisible disabilities?

Participant 1:I think, it's such a difficult task. You know what I mean? I don't think there's any one way to fix the giant problems that society has, dealing with disabilities, let alone Portland State. I think the DRC is really commendable. I think the people they have are incredibly approachable. I think they've made safe spaces for people. I think all of the staff that I've interacted with, and everything, I don't think, other than I get too many emails. I don't think there's a single complaint.

Speaker 1:That's so honest!

Participant 1:It is! There's so many emails! Other than that, I don't think there's anything I could say that's negative. On behalf of Portland State, I think just the student on-boarding interface. I feel like all incoming students should have, you know, some kind of welcome packet or some sort of, you can't register until you sit down with someone, right? It could just be a five-

Speaker 1:Guidance.

Participant 1:... yeah. It could be a five minute check-in for people that don't have any disabilities of any kind. Then, for the people that do, or think they might, or whatever, just a little hey, how you doing? Let me give you a list of the myriad resources we have. Because there are so many. I didn't know that until I was here for a while. If I had known those things as a freshman, I can't even imagine how different my experience would have been. Especially in those first couple of years. 
STUDY OF EQUITABLE ACADEMIA FOR STUDENTS WITH DISABILITIES

Participant 1:I worked at Vanguard, the newspaper. I worked there for a long time. A year and a half, almost two years. It was only when I started working there that I really got clued into the Portland State community. That I really started feeling like I was a part of this school. Because I'm training reporters and going out and getting interviews with people, and I was just finally like this member of this community.

Participant 1:Before that, I felt more or less invisible. Not like with my teachers. I have the

Speaker 1:It's a big school.

Participant 1:Yeah. I've always built a rapport with teachers and the college that I'm in, and the Honors College, and different students. I built my own community individually, but I did not feel like I was a Portland State community member until I joined Vanguard. I feel like some kind of come to Jesus first meeting for anyone. Freshmen, transfer students, doesn't matter. If you're new to Portland State, look at all these things we have going on because there is a place for everyone here. You just need to find your people and let's help.

Participant 1:There's so many sub student groups, there's like 140, right? There's so many different departments. There's so many different things going on. All the resource centers. People just don't know. Or if they do, that would be a good question. How did you find out about that so quickly?

Speaker 1:Right. Absolutely.

Participant 1:I didn't.

Speaker 1:If somebody was nervous about seeking accommodations from the DRC, what advice would you give them, potentially? 
STUDY OF EQUITABLE ACADEMIA FOR STUDENTS WITH DISABILITIES

Participant 1:I mean, don't be. That's not fair, right? That's like telling a crying person to stop crying. No. That that's totally normal. It's totally normal to think that. My thought was, I don't deserve accommodations, I'm able-bodied. I don't have a learning disability. I have great grades, you know? Am I even qualified? This is the same conversation I had with my therapist. Like, how could I Have PTSD? That's what people get when they go to war.

Participant 1:I'll never forget what she said. She goes, "Well, you know, some people go to war and never get PTSD." That's like, what? This just leveled everything out. Okay. Everybody reacts differently to everything and it's totally okay. To me, even thinking that you need help means you're on the right track. If you even think that you might want some help, then you're doing the right thing. Participant 1:The people that don't acknowledge that they need help, that's harder. That's a harder place to be. I lived there for years. You just can't. You can't help the people that aren't ready yet, to ask for help. The fact is, we all need help. We all need help. Everybody needs help with something, right? So what do you need help with? That's what I wish I had had right when I started. How can we help you? Or how can I find someone else to help you? What is it that we can do for you? Saying you need nothing means you're already failing. Participant 1:Okay, well that's great. That's going to suck for a while. Let me know when you get out of that.

Speaker 1:Well Participant 1, thank you so much.

Appendices 2

Participant 2 
STUDY OF EQUITABLE ACADEMIA FOR STUDENTS WITH DISABILITIES

Participant 2:Yeah.

Speaker 1:Alright. So Participant 2, how did you decide to come to Portland State?

Participant 2:So I originally was a music education major, and I visited Portland State and

they had a great music program. And I was told about the [inaudible 00:00:15] program

which was $100 \%$ job for you out of school, and I'm like yeah, I would like that.

Speaker 1:That's pretty nice.

Participant 2:I ended up changing my major, but I'm glad that I picked Portland State just because it got me out of my home down in southern California.

Speaker 1:Oh yeah.

Participant 2:Yeah.

Speaker 1:And how long have you been living in Portland?

Participant 2:This will be my end of the second year of me being here.

Speaker 1:Okay.

Participant 2:Yeah.

Speaker 1:Yeah. Did you know anyone in Portland?

Participant 2:No.

Speaker 1:Oh, so you just came in?

Participant 2:Yeah.

Speaker 1:Fresh.

Participant 2:Yeah. It was a little overwhelming, but it kind of made me grow up and

figure things out for myself. Because I was kind of on my own.

Speaker 1:Yeah.

Participant 2:I could call home, but they couldn't physically do anything for me. 
STUDY OF EQUITABLE ACADEMIA FOR STUDENTS WITH DISABILITIES

Speaker 1:So what type of... How did you find support here at Portland State? Meaning, how did you find community, a sense of community?

Participant 2:I was really lucky getting the roommate that I did. Being trans you kind of get grouped up with trans people, and that's just how housing does it. And I still live with them, and we're moving into a townhouse together.

Speaker 1: That is awesome.

Participant 2:Yeah. They became my best friend, and it's great. I got lucky getting the friend that I did as a roommate. But after that it was kind of building friendships through classes to try and be like oh, let's have a study group and try and meet people outside of classes. Just because otherwise I knew I'm not going to actively... I tried going to the QRC as a freshman, and it was just not for me personally. So it was easier for me to make oneon-one connections rather than going to big events kind of thing.

Speaker 1:Mm-hmm (affirmative)- Can I... If you feel comfortable...

Participant 2:Yeah.

Speaker 1:Why wasn't the QRC for you? What was the...

Participant 2:Part of it was my freshman group of friends kind of... we all sort of drifted apart for one reason or another, and they still kind of hang out there. So it was something where it's like it didn't feel like it was my space anymore. It's not the QRC as the people that run it or the space.

Speaker 1:Right.

Participant 2:It just sort of I feel a disconnect from it now being I have my own QRC within my family of friends that $I$ have. 
STUDY OF EQUITABLE ACADEMIA FOR STUDENTS WITH DISABILITIES

Speaker 1:Yeah. I think it's really interesting to talk about space and community space,

especially here at Portland State.

Participant 2:Yeah.

Speaker 1:So what made you register or seek accommodations with the DRC?

Participant 2:So this year has been a little rougher than freshman year as far as academics and stuff go. I had accommodations in high school because I had a myriad of things that happened and I just got to my senior year and I'm like, I need people to be aware of what's going on.

Speaker 1:Mm-hmm (affirmative).

Participant 2:And I realized I could actually take advantage of those here. I didn't... I asked... Both my parents are high school teachers. I'm like, "Do they follow you to college?" And they're like, "Yeah, you just have to go talk to the disability resource center." So I did, and it's been kind of a... This is the first term that I haven't had to go back in to make sure everything was clear.

Speaker 1:Mm-hmm (affirmative).

Participant 2:It's been nice having those accommodations with being able to exit the classroom if I'm in a state of panic or say can I know about this test in advance just so it's on my mind? Recently being diagnosed with ADHD I'm like oh, that makes a lot of sense. And I haven't gone back into the DRC to talk about that, but it's nice to know that I have that place if I need to...

Speaker 1:Definitely.

Participant 2:Get help academically. 
STUDY OF EQUITABLE ACADEMIA FOR STUDENTS WITH DISABILITIES

Speaker 1:Yeah. Absolutely. How has been the relationships with your professors

communicating this or trying to... I don't know... successes and failures in the classroom

environment as a whole?

Participant 2:It's been a lot nicer since getting the DRC accommodations because there's automatically the email that's sent just to let you know this student has these things, and usually that helps professors reach out to me. Because I have a tendency coming from the family that I do with teachers, I know it's important to talk to your professors, and I've been very upfront since freshman year about here are the things that might happen. So I think I'm pretty good at seeking out knowing that my professors know what's going on. Speaker 1:Yeah.

Participant 2:But with the DRC it's been really nice because if I don't initiate that it still happens anyway so that they're just aware that this is someone that's in your class.

Speaker 1:Right.

Participant 2:And this might... It's not anything against your class or you as a professor. It's just things that go on.

Speaker 1:Definitely.

Participant 2:Yeah.

Speaker 1:It seems like self advocacy has been a big part of your life.

Participant 2:Yeah.

Speaker 1:How have you learned to navigate that being a college student?

Participant 2:The hard way I would say.

Speaker 1:Yeah. 
STUDY OF EQUITABLE ACADEMIA FOR STUDENTS WITH DISABILITIES

Participant 2:Just kind of being forced into it. I would say the difference between high school and now for me is 180 in the sense of [crosstalk 00:04:49] actually doing things for myself. Not that I didn't at home, but freshman year I was calling my parents a lot more being like, "Am I allowed to go talk to these people or do this?" It's really had to not be beaten into me, but kind of over time just really understand the fact that if you don't do something, nothing will come of it.

Speaker 1:Mm-hmm (affirmative).

Participant 2:Most professors aren't going to automatically just reach out if they see you. I think I'm lucky in the major with child, youth, and family studies... Speaker 1:Yeah. Great major.

Participant 2:Most of the professors are pretty one on one relationships, so they'll notice if something's up. But I know for the most part that's on me. If I want help, I need to ask for it.

Speaker 1:Mm-hmm (affirmative).

Participant 2:Yeah.

Speaker 1:So where have you found success at Portland State?

Participant 2:Definitely in the child, youth, and family studies program. I was lucky that I switched when I did just because it hasn't been that hard of a transition between music and-

Speaker 1:Oh, you switched from music. Right.

Participant 2:Yeah. So I originally was music education, and now I'm just the social work... school and social work and education portion of it.

Speaker 1:Yeah. 
STUDY OF EQUITABLE ACADEMIA FOR STUDENTS WITH DISABILITIES

Participant 2:And it's been pretty easy. I got to the end of my freshman year, and I'm like,

I don't think college level music is for me.

Speaker 1:Mm-hmm (affirmative).

Participant 2:I had a professor who I still have now. I've taken her classes. Try to take one a term because she's great. And it's been really nice kind of getting a community in there. Speaker 1:Right.

Participant 2:Because you see a lot of the similar faces in different classes because we're in the same school and major kind of thing.

Speaker 1: What have been obstacles with Portland State just as a whole?

Participant 2:Navigating everything, whether it be transportation, not being from here, knowing... I feel like even though it's my second year, knowing how much time it takes to get from class to class if it's in a different building. Being with the DRC, they try to have as many classes in Cramer as possible, which is great, but then it's like oh, this class can only be in the Fourth Avenue Building. I'm like okay, I got to... Yeah.

Speaker 1:That's far.

Participant 2:Yeah. So kind of figuring those things out. And I know part of it is on me. Within the last two terms I'm just like yeah, it'll be great having classes back to back. So I choose to do that not thinking about the distance. So it's nice knowing that $I$ have people at the DRC that are looking out for me, but also that's been something that I keep forgetting to take into account when looking up classes. Because I never know how my chronic pain will be day to day. I never know how traffic-y foot traffic will be.

Speaker 1:Right. 
STUDY OF EQUITABLE ACADEMIA FOR STUDENTS WITH DISABILITIES

Participant 2:So that's been one of the harder things, getting around and making sure

I'm... I come from a family of if you're not early, you're late. So that's just kind of...

Speaker 1:Oh my gosh. I relate to that.

Participant 2:Yeah.

Speaker 1:Deeply.

Participant 2:Yeah. Getting somewhere 10 minutes early and no one's there I'm like, "Am I in the wrong place?"

Speaker 1:Forgive me. You don't live on campus right now?

Participant 2:I do.

Speaker 1:Oh, you do live on campus right now.

Participant 2:Yeah. I live in Ondine.

Speaker 1:Oh wow. How has that community space been?

Participant 2:I'm not a fan of housing personally just with the way that they've treated some things. My roommates in the future, we're moving into a townhouse tomorrow... Tomorrow. Next week. Sorry.

Speaker 1:It's fine.

Participant 2:And we're all trans, and so housing has issues with that. Not openly, but just... My boyfriend got roomed with a cis woman moving in and then has gone through three different roommates to try and...

Speaker 1:Wow.

Participant 2:Yeah. You know, you don't want to be living with someone that you bicker with constantly.

Speaker 1:Absolutely. 
STUDY OF EQUITABLE ACADEMIA FOR STUDENTS WITH DISABILITIES

Participant 2:I got lucky with my roommate, but we also have a suite mate who hates us.

It's just kind of...

Speaker 1:Oh yeah.

Participant 2:I mean they're 28 living in the dorms, where I feel like neither us were late being 20 and being not from here. So we can't just go home on the weekends kind of thing. Speaker 1:Yeah.

Participant 2:But everyone needing their own space and it's not really a place for having your own space because it's the size of this room and two people are living in it.

Speaker 1:Yes. Yes. I also live in housing. I relate deeply to that.

Participant 2:So I love the people, the students, and the people that I live with for the most part because I seek that out. But as far as housing overall, I'm just not a fan of how they handle things sometimes. So that's why we're trying to move out.

Speaker 1: What would you want them to change? Their discourse, the way they house people, the communication?

Participant 2:I think kind of all of it. I feel like they aren't the best at communicating openly about why it is they do certain things. Like my boyfriend having to ask, you know, here I said explicitly I'm a trans man. I don't want to be roomed with a woman. This kind of thing. And they have to go through the process of messing that up multiple times and forcing him to move, not giving him a choice even if he liked... There was a roommate he liked even though she wasn't trans where it was just kind of like I'm comfortable here, but also you're not going to let me live because you realize that I'm a man. It's just kind of... Speaker 1:Right. 
STUDY OF EQUITABLE ACADEMIA FOR STUDENTS WITH DISABILITIES

Participant 2:I feel like they didn't handle that very well. And when we've asked about things like our suite mate moved in six weeks into last term where it was kind of weird. We thought we just weren't going to have a suite mate because there was no one there fall term. And then it was move in and just uncomfortable with one another. Because we've all... we've been taking up so much space because no one else was in there, and I feel like we didn't get any notification. It was just kind of one day they were there.

Speaker 1:It's very taxing.

Participant 2:Yeah.

Speaker 1:You know? It's also very stressful to live in that constant state of uncomfortableness. Participant 2:Yeah.

Speaker 1:And then have to take that to class.

Participant 2:Mm-hmm (affirmative).

Speaker 1:And attribute that. What do you think the DRC could do better? And what do you think the DRC is doing well?

Participant 2:I think the DRC... Personally I wish there were people more reaching out just to see. I know that takes a lot of people to do with the amount of students that go to the DRC. But I have issues with actively reaching out to be like, you know, I think I need to change my accommodations or anything that I can't do online. It takes me a while to actually set up an appointment to go and do that. So I feel like maybe if there was more of a reach out besides the weekly Wednesday email where it was kind of just a one term thing being like, "Hey, is there anything you need to change or you want to come in and set up an appointment?" Just because I know I'm probably not the only one, but personally I have 
STUDY OF EQUITABLE ACADEMIA FOR STUDENTS WITH DISABILITIES

issues with reaching out if I feel like it's kind of a burden of you have this large student body that you're looking out for. I know one individual isn't the difference, but...

Speaker 1:Yeah.

Participant 2:Yeah.

Speaker 1:And then what about the successes of the DRC? What do you find helpful? You mentioned the Wednesday weekly.

Participant 2:Yeah. I really like the emails about closures and stuff. Being someone who uses the elevators for the most part, it's nice to know if there aren't signs posted that oh, the one in Smith isn't working today, so I have to go through Cramer to get over there. Speaker 1:Mm-hmm (affirmative).

Participant 2:That's pretty nice. Because usually I get them far enough in advance that I can kind of plan around that.

Speaker 1:Yeah.

Participant 2:I know DRC isn't connected with housing, but I feel like if they were, so many... You live in housing.

Speaker 1:Yes.

Participant 2:So I feel like elevators never work in any of the buildings.

Speaker 1:No.

Participant 2:So that's just...

Speaker 1:They just don't work. They're just props.

Participant 2:Yeah. Which I feel isn't fair for students that have to use the elevators. Speaker 1:Yes. 
STUDY OF EQUITABLE ACADEMIA FOR STUDENTS WITH DISABILITIES

Participant 2:I live on the 15th floor of Ondine, so I'm like, if I don't use the elevator I'm just going to wait.

Speaker 1:Oh, 15th floor. Oh yeah.

Participant 2:Yeah.

Speaker 1:Oh my goodness.

Participant 2:Yeah.

Speaker 1: What about the classroom climate at Portland State?

Participant 2:What do you mean?

Speaker 1:Meaning the classroom set up, the environment that the teachers give the students.

How has that been for you?

Participant 2:I've been really comfortable in all the classes I've had besides maybe two giant lecture halls where it was kind of not really reading the number of students that would be in the class and being like oh, this is a 200 person lecture. So that's nothing that the professor can control. That's just something that I personally prefer to not take huge lectures because I feel like I am not as comfortable in a setting where everyone's kind of crammed together.

Speaker 1:Yeah.

Participant 2:But I feel like from joining the DRC it's been great as far as getting chairs that are comfortable and at least people knowing it. Even if people sit in the DRC chairs, they're there if I really need it that day kind of thing.

Speaker 1:Well, I think that's it.

Participant 2:Okay.

Speaker 1:Yeah. Thank you so much 
STUDY OF EQUITABLE ACADEMIA FOR STUDENTS WITH DISABILITIES

Appendices 3

\section{Participant 3}

Speaker 1:Okay Participant 3. Thank you so much for sitting down with me. Why did you decide to come to Portland State?

Participant 3:One of the reasons was because it's close to my house.

Speaker 1:Okay.

Participant 3:I live on Southeast of Portland. I don't have to travel long distance, like go to Oregon State or-

Speaker 1:Yeah, definitely.

Participant 3: That was one of the reason. Second reason is because $I$ heard good news about Portland State. It's a good school, and I expense [inaudible 00:00:36]

Speaker 1:Yeah. Now do you take public transportation to come here?

Participant 3:Most of the time, yeah.

Speaker 1:Okay, how long would you say that takes you to get from your house?

Participant 3:It's about an hour.

Speaker 1:About an hour. Okay

Participant 3:An hour from here to my house, and an hour from my house to here.

Speaker 1:Do you have to plan in advance when you come? Do you check any of the transit websites?

Participant 3:No. I'm a person that need to be there on time.

Speaker 1:Oh okay.

Participant 3:Psychologically. I even leave an hour and a half to two hour ahead of time because I want to make sure that by the time, I'm going to be there. 
STUDY OF EQUITABLE ACADEMIA FOR STUDENTS WITH DISABILITIES

Speaker 1:Definitely.

Participant 3:In fact, for this interview, I left about an hour ahead of time.

Speaker 1:Oh wow.

Participant 3:My kids dropped me off, but I want to make sure that I was going to be here on time.

Speaker 1:How does that, how does it make you feel when we have winter storms, or weather advisories?

Participant 3:It's really difficult because you never know about the schedule.

Speaker 1:Yeah.

Participant 3:I use to drive for TriMet.

Speaker 1:Oh wow.

Participant 3: When snow come, the schedule is out of the window.

Speaker 1:Definitely. Yeah, very frustrating.

Participant 3:I leave about two to three hour ahead of time.

Speaker 1:Wow.

Participant 3:Sometime I still get there late. When I get there late, for me it's likeSpeaker 1:Makes you anxious?

Participant 3:Yeah.

Speaker 1: Why did you decide to seek accommodations or guidance from the DRC?

Participant 3:I get my associate in Portland Community College. When I was there, my Advisor advised me to get in contact with the student disability office in Portland Community College. When I was about to graduate, I asked the advisor from there if there is an advisor here. 
STUDY OF EQUITABLE ACADEMIA FOR STUDENTS WITH DISABILITIES

Speaker 1:Oh okay, so you had some support?

Participant 3:Yeah. They said, "Yeah, yeah. Go there Thursday where they have the DRC and they'll help you out and other things." So I came here and first thing I did was thing, what's it called, the financial aid. Second thing was the DRC.

Speaker 1:Oh wow. How was that process for you? Was it a long process, or was it pretty easy to get accommodations from the DRC?

Participant 3:No, once you have the document from the doctor that you have some kind of disability.

Speaker 1:Right.

Participant 3:You make an appointment like today, I can make an appointment for

Wednesday.

Speaker 1:Oh wow. Okay.

Participant 3:Yeah.

Speaker 1:So pretty quick.

Participant 3:I went there and they said, okay, you need this, you need this, you need this, you need this, you need this, you need this, you need this, and okay. Everything is accommodated.

Speaker 1:Oh that's awesome.

Participant 3:Yeah. It took about half an hour total.

Speaker 1:Woohoo. That's pretty good.

Participant 3:Yeah, I'm really happy with the DRC here.

Speaker 1: What would you say are the benefits of having a Disability Resource Center on your campus? 
STUDY OF EQUITABLE ACADEMIA FOR STUDENTS WITH DISABILITIES

Participant 3:I understand that my disability is not visual. I don't carry wheelchair, I don't carry walker. I can move-

Speaker 1:Freely.

Participant 3:Freely. But my disability is mental

Speaker 1:Okay.

Participant 3:They didn't judge me. They didn't say, "Well, we have to triage and you're not the priority." They said, "You are here, you are the priority."

Speaker 1:Wow.

Participant 3:They immediately accommodate me. For example, I have a desk in each class. I don't take classes in school right now because I'm doing an internship.

Speaker 1:Oh wow.

Participant 3:And a class in Coffee Creek.

Speaker 1:Cool.

Participant 3:Yeah, it's really fun. But when I have a class here, I have a desk for myself. I have a chair that help me with my back.

Speaker 1:Okay.

Participant 3:I have somebody who take notes for me because if I listen to you, I can't take notes. If I take notes, I can't listen to you. That is one of the disability that I have.

Speaker 1:So lots of support in the classroom environment. [crosstalk 00:05:47] How is the internship that you're doing?

Participant 3:I'm taking an internship for AARP. Speaker 1:Oh, what is that exactly? 
STUDY OF EQUITABLE ACADEMIA FOR STUDENTS WITH DISABILITIES

Participant 3:AARP is for people that are 50 or over. They help them with how to manage POs, they do field trips, they do all kind of ... There are like 57 million people in it. Speaker 1:Wow.

Participant 3:It's 53 offices in the country. Speaker 1:Oh my goodness.

Participant 3:Yeah, it's the all 50 states, plus Columbia and two states, Hawaii. It's really, I love it. I start my internship with a agency called Elders in Action, which was about the same thing, but much, much, much smaller.

Speaker 1:Okay.

Participant 3:Because of funds, they had to shut that down, the door down.

Speaker 1:Oh interesting.

Participant 3:Yeah. Thank goodness the last meeting, there was a AARP officer there. I asked him, he said "Yeah, come over there and we sign you up." I'm 50 now, so for me it's, that's what I would like to do.

Speaker 1:Yeah.

Participant 3:Become an advocate for older people.

Speaker 1:That sounds really rewarding, and really interesting.

Participant 3:Yeah.

Speaker 1:This was an internship through Portland State?

Participant 3:Portland State, well, Portland State, they give you whole bunch of, I'm a Criminal Justice student.

Speaker 1:Yeah, yeah. 
STUDY OF EQUITABLE ACADEMIA FOR STUDENTS WITH DISABILITIES

Participant 3:I'm getting my Bachelor in Criminal Justice. They give you whole bunch of sites from Sheriff's Department to State police, to US Marshall, to FBI. Speaker 1:Wow.

Participant 3:All those kind of sites. But there was, because of my age, places like the police department and stuff like that, for me, are a dead end. I used to be a policeman when in was in Italy.

Speaker 1:Oh wow.

Participant 3:But that was when I was 25. Now I'm 50. I'm too old and too fat to become a cop. It was not to be in that position for me. My teacher, can I say her name?

Speaker 1:Yes.

Participant 3:Dr. McGorry which I love her to death. She was the one who said, "Mass, why don't you apply for a place like for older people, or teenagers?" I don't have much patience for teenagers. So I decide to go with the older people and actually see it. With this position, it's not just me being, doing an internship, but it's first position that I can get hired at the end. Second, it give me motivation.

Speaker 1:Oh that's great.

Participant 3:I enjoying going to work.

Speaker 1:Yeah.

Participant 3:And donate my time. It help me helping other people.

Speaker 1:Yeah, what more could you ask for?

Participant 3:Exactly.

Speaker 1: That seems great. 
STUDY OF EQUITABLE ACADEMIA FOR STUDENTS WITH DISABILITIES

Participant 3:My father always said that when you're enjoying the job that you're doing, you don't work a day in your life.

Speaker 1:Exactly. So you mentioned you moved from Italy to the U.S.? When did that happen?

How long have you been here?

Participant 3:I moved in United States in 1992.

Speaker 1:Okay.

Participant 3:I moved in Portland in 1996.

Speaker 1:Oh wow.

Participant 3:When we were in Italy, we stay four year in Italy after I got married with my wife. Then happen, I got injured in the line of duty, and it was too stressful for my wife to come to the hospital to see me. Then she had a toddler, we had a toddler and a newborn. Speaker 1:Oh my goodness.

Participant 3:So it was too stressful for her. So I said, "Let's, we stay four years in Italy. Let's go to Chicago for four years," where she's from. We were about to go back to Italy because Chicago is a beautiful city, but it's not a place I want to raise my kids.

Speaker 1:It's very tough.

Participant 3:It's very tough. It's very cold. It's very hot and humid in summer. Speaker 1:Oh yeah.

Participant 3:Crime is overwhelming. We were about to go back to Italy, but we came here on vacation one year, and we just fell in love with Portland.

Speaker 1:Oh yeah?

Participant 3:So we said, "Okay, let's move to Portland for four years and decide where to stay." Now we're here for 26 years. 
STUDY OF EQUITABLE ACADEMIA FOR STUDENTS WITH DISABILITIES

Speaker 1:Oh my goodness. What has it been like being an immigrant at the University?

Participant 3:Being an immigrant at the University, I believe that my experience was different than the experience of some other country fellow.

Participant 3:People treat me, not only at the University, everywhere, people treat me kind of strange way, until they hear that I'm Italian.

Speaker 1:Oh okay.

Participant 3:Then everything is beautiful and fun. People love Italian people. I don't know why. People love the food. People love, they are so proud to have ancestry from Italy. It was, it's kind of sour, sweet experience. With the teacher, I never had any problems. Speaker 1:Okay.

Participant 3:The teacher always treat me like they treat everybody else. Speaker 1:That's good.

Participant 3:With respect. With the students, $98 \%$ of the time was fine, was nice. There's only couple percent of people that are like-

Speaker 1:Eh, so-so.

Participant 3:Like I said, they treat you like oh you are from Muslim country, or you are from Mexico, or you are from Mexico.

Speaker 1:Wow.

Participant 3:So they treat you different until, especially when I have the beard, I guess I look a little bit Mexican.

Speaker 1:It's interesting they would assume.

Participant 3:Yeah, they assume a lot.

Speaker 1:Yeah. 
STUDY OF EQUITABLE ACADEMIA FOR STUDENTS WITH DISABILITIES

Participant 3:Then they hear I'm Italian. They're like, oh in Italy the women are so beautiful.

Speaker 1:So it switches quick.

Participant 3:Yeah.

Speaker 1:Wow, that's interesting. Where have you found success at Portland State?

Participant 3: Where did I find success? With this teacher, Dr. McGorry, She answer emails almost immediately.

Speaker 1:Oh wow.

Participant 3:I can text her now, and by the time I get home, I have the answer. Speaker 1:Oh, that's so good.

Participant 3:That's why I don't take online classes because I need to see the teacher's body language to be able to understand what she mean.

Speaker 1:Right.

Participant 3: With Dr. McGorry, she, I wish that there was a prize to give to those teachers because she never complained that I email her, and I email her a lot because of my language, and because of my disability. I have a hard time to understand part of the syllabus.

Speaker 1:Okay.

Participant 3:My wife help me a lot because she has a Master in Geology. Speaker 1:So cool.

Participant 3:She is a smart girl. I don't know why she married me. When I have a question, I email her immediately and she answer me. She told me more than once, "Mass, don't say I'm sorry for when it's not needed." You know? 
STUDY OF EQUITABLE ACADEMIA FOR STUDENTS WITH DISABILITIES

Speaker 1:Yeah, it's a good teacher.

\section{Participant 3:Yeah.}

Speaker 1:How has it been with teachers who aren't like this one? How do you navigate that?

Participant 3:It was hard. It was really hard. There was one teacher, gosh, that was the worst class I took. Thank goodness I had another student that he is 4.0 average student. He helped me out with the homework and stuff like that.

Speaker 1:Oh wow.

Participant 3:We kind of, I was lucky enough to hang on a relationship with him.

Speaker 1:Pardon. Sorry, that's my phone.

Participant 3:They, the teacher, was saying things that was really hard to understand for me. Plus, when he give tests, it was, they were really confusing.

Speaker 1:Were they multiple choice?

Participant 3:Multiple choice. I usually love multiple choice, but the answer wasn't exactly what he taught.

Speaker 1:Right. So maybe the content that he was teaching didn't match with the-

Participant 3:The test.

Speaker 1:The test. Yeah. Did he have lots of, like did he do a presentation, like a PowerPoint, or was it-

Participant 3:He had a PowerPoint, but I head a lot of bad things about that teacher. So it wasn't just me. It was-

Speaker 1:It was other people too.

Participant 3:Other people too that complain about him. I had, it wasn't because the class was hard. I had another teacher that her class was Statistics. 
STUDY OF EQUITABLE ACADEMIA FOR STUDENTS WITH DISABILITIES

Speaker 1:That's hard.

Participant 3:That's a hard class. Especially for me because I have, one of my disability is I suck in math. My brain, the way math work, is not the same way math works. I did a psychological evaluation about that. But she stayed overtime, she came over here on Saturday. She had a person, what you call it, student-

Speaker 1:TA?

Participant 3:TA?

Speaker 1:Yeah.

Participant 3:That was helping students with homework. She did that, her best, to help her student succeed. This guy, he did nothing about helping his student succeed. He just, you can feel that he was there to get a paycheck and then [inaudible 00:18:11]

Speaker 1:Yeah, that doesn't feel good to be a student in that.

Participant 3:Exactly.

Speaker 1: What has been the biggest barriers for you at Portland State? That could be academic, social, or even things like transportation, or you know?

Participant 3:I think that Portland State should do some kind of, like I said, I used to work for TriMet. It doesn't matter if you're a student or not. When you are 18, you don't have discount anymore. Unless you're a person like me that has a Senior Citizen discount. Portland State should do something to facilitate a student on getting transfers. Transfers are \$2.50.

Speaker 1:Yes. Yes they are.

Participant 3:Transfers. For some studentSpeaker 1:It's a lot. 
STUDY OF EQUITABLE ACADEMIA FOR STUDENTS WITH DISABILITIES

Participant 3:It's a lot of money. Even you pay the whole day, it's for \$5. Five days, \$5 a day for five days, it's a lot of money. Portland State should do something to facilitate students with transfers.

Speaker 1:Yeah.

Participant 3:That's one thing that I think they should happen. Academic, you know, in all the classes that I took with Portland State, that bad teacher was the only one that I had. Speaker 1:Oh, that's good.

Participant 3:Yeah. All the other teachers, they, you can feel, especially if you take classes with Dr. McGorry, you can see in her face that she's really involved. She's, "Come on. I know you know the answer." You know?

Speaker 1:Engaging.

Participant 3:Engaging. Yeah.

Speaker 1:Yeah.

Participant 3:But all the other teachers are the same. You can feel that they are to give an education. They love the job that they are doing, and they have a purpose.

Speaker 1:Yeah.

Participant 3:And the purpose is not only getting a paycheck at the end of the month. Speaker 1:Right, definitely. If somebody was nervous about registering for the DRC, but wanted to register, what would you say to them?

Participant 3:Put your worries aside. Just go there. I was nervous going to the DRC even in PCC. I don't know what questions they ask me, they will ask me. They don't give you a test. It's not like a it's a right or wrong questions that they ask you. Speaker 1:Right. 
STUDY OF EQUITABLE ACADEMIA FOR STUDENTS WITH DISABILITIES

Participant 3:They're there to help you. They are there to guide you. You have way more facilitations that you don't even imagine. I have an app on my computer that actually read the books to me.

Speaker 1:Wow. Yeah.

Participant 3:It reads and it highlights the phrase that it reads. It reads in four or five different accents.

Speaker 1:Oh my goodness, that's cool.

Participant 3:So you have the visual, you have the reading, and you have the listening. All you have to do is buy the book. You go to DRC, you show the receipt, in two, three days, they send you the book, the whole book on your computer.

Speaker 1:So they really try to help the student and meet them where they're at.

Participant 3:Exactly.

Speaker 1:Wow. It seems like you'll be very, I'm sorry, go ahead.

Participant 3:Put your worry aside and it's something new, but there's nothing, really nothing to worry about.

Speaker 1:It seems like it would be very difficult to know you might need accommodations and push through regardless.

Participant 3:Yeah, I didn't know that there was that kind of app on the computer. I didn't know that I could get a desk for myself.

Speaker 1:Yeah.

Participant 3:I didn't know that I could have somebody write notes for me. I had the same thing in PCC, but you know, PSU is a different story. Speaker 1:Yeah. 
STUDY OF EQUITABLE ACADEMIA FOR STUDENTS WITH DISABILITIES

Participant 3:You don't even have to contact your teacher. They contact your teacher for you.

Speaker 1:Oh that's so nice.

Participant 3:And let them know, "Hey, this guy need this. Needs this, this, this." It's the teacher's job to tell the students, "Hey, if you're a good note taker, you want to ..." But even for people who don't need the DRC, they need note takers.

Speaker 1:Yeah.

Participant 3:And note takers get paid \$25 a credit.

Speaker 1:Oh yes, that's true.

Participant 3:You know?

Speaker 1:Win Win.

Participant 3:Win Win situation. I had note takers for $95 \%$ of the classes that I took, and I succeed in $95 \%$ of the classes

Speaker 1:That's awesome.

Participant 3:Well 98\% since I now have 22

Speaker 1:That's awesome. I think that's it for the interview.

Participant 3:Okay.

Speaker 1:Thank you so much.

Appendices 4

Participant 4

Participant 4:... I worked with kids, and I worked with dying people. Working with dying people in care situation I sought to work with children, but it just never materialized, 
STUDY OF EQUITABLE ACADEMIA FOR STUDENTS WITH DISABILITIES

because you get one patient at a time. Because half this is required to have a certain

number of hours, but they try not to overload the volunteers.

Participant 4:So it's like a different [inaudible 00:00:31] it's [inaudible 00:00:32]

Speaker 1:Oh, you're breaking up a little bit, just slightly.

Participant 4:Huh.

Speaker 1:Oh, I can hear you clear now.

Participant 4:Okay.

Speaker 1: Where did you find success at Portland State?

Participant 4:Oh, so I was going to say, it took me two times to get into this program, because Portland ... So, Portland State, it's a big university, and it has many different schools in it, and those schools have varying levels of demand. The social work program is in high demand, so ultimately, once I got back to being a blind person, declared a blind person, I applied again, and I didn't get in.

Participant 4:They said that the only weak part of my application was experience, but I actually don't think that was the case, I think it was the way that I wrote about myself. So, what I did is I submitted a paper that was really thorough and inventive on a particular programming that could be implemented, and I just cited every [inaudible 00:01:52] four times. So I was just basically being like, "I can write a paper in APA style, and I can think about programming in non-traditional ways."

Participant 4:So, I just really pushed that to the forefront, and not how much I cared. I think that that's what got me in that time. Because it's like for every one person in my program, it's like three or four people are turned away.

Speaker 1:Oh, wow. Very competitive. 
Participant 4:Yeah, so, I finally got in, and I was pregnant when I applied this time, and I was working a bunch of jobs, so I still wasn't finding any sort of fulfillment. So, when you asked what was the reason for going to Portland State, it was because there was pressure. One, from timing, right? You know, I had family concerns, so the type of program was dictated by that. It's not as difficult of a program time-wise as other options career-wise. Participant 4:It's a less expensive option, so easier to negotiate with the vocational rehabilitation people. I had already applied for the program once, so it kind of seemed like all right. It also seemed like my last chance, because I just had a baby, you know? I was just about to have a baby. So, I was thinking, "Well, if I don't do this now, then I'm going to have to put this on hold and just, you know, have a bunch of children now and call it good. Then come back in five years and think about this." Participant 4:So, it was a lot of reasons, but if you're thinking about, "Well, what about disability?" I think that scaring, you know, interaction where I basically was like, "Okay, I'm not going to go to, because you guys are idiots." You're thinking that this is actually going to protect you legally, no, that would not protect you legally from a lawsuit. What they did right there wasn't enough to have a lawsuit, I'm pretty sure, and if I was really pissed about it, but I could care less. I'm like, "I got other stuff to do." Participant 4:But it did show me that they really were not a place for people with disabilities. I have worked in the past with PSU, but honestly, that was the least consideration, was how good are the disability services?

Speaker 1:Oh, interesting. 
STUDY OF EQUITABLE ACADEMIA FOR STUDENTS WITH DISABILITIES

Participant 4:Yeah, it wasn't, it was, "Can I get my funder to pay for a full ride? Because I'm not willing ..." I just paid off my undergrad, I'm not willing to go back into debt for school.

Speaker 1:Yeah.

Participant 4:So, that was the primary consideration for me going into a professional degree. So, I wish I could say something that might be more supportive to ... Because as a social worker that's emerging, it is my duty to only make comments and steer research toward strengthening services for people who I will be serving.

Speaker 1:Mm-hmm (affirmative). Right.

Participant 4:So, I wish I could say something that is ... that was along those lines, but I can't. But I will say that I am a lot less stressed out, that I ended up picking a school that has a way to interface in a, I would assess, pretty functional way, like give them at least a $\mathrm{C}+$ or minus.

Speaker 1:Yeah. Well, I really appreciate you walking me through your journey of going to Portland State. It seems like it's been ... it was a long road to get to where you are now. What was the success that you found once you were at Portland State? So once that decision was made that you're going, where did you find success here?

Participant 4:So far it has been a very different ... Since I'm a non-traditional student, even for a graduate student, non-traditional, meaning that I am a parent of a small child. I started fall quarter of 2018, and my child was four and a half months old. Speaker 1:Wow, little one.

Participant 4:Yeah, I went to my orientation when she was five weeks old. It was my first time that I was an hour away from her or more. 
STUDY OF EQUITABLE ACADEMIA FOR STUDENTS WITH DISABILITIES

Speaker 1:Wow.

Participant 4:Uh huh. It was really hard.

Speaker 1:That's very hard, yeah.

Participant 4:Yeah. So, I've been trying to learn how to interface with parent services, along with disability services, and they are separate services. So, my success, I would actually say the note-taking has been incredibly useful because I nurse in class. You know, I have to pump.

Speaker 1:Mm-hmm (affirmative).

Participant 4:Because I'm in the social work program, I can't actually fully utilize the lactation rooms, I'll use it for cleaning up, storing my milk, taking a breather if I can't lactate in class, because we're talking about something very distressful. That is a thing, a lot of women need to relax to lactate.

Participant 4:So, the note-taking usually is something for visual thing, right? But in this case, I can't use my hands at all for portions of class, because I'm holding up the nipple shield.

Speaker 1:Mm-hmm (affirmative).

Participant 4:I mean, I don't want to do it in class, but it's ... I would miss so much if I stepped out for half an hour to pump, so, it's my only option. That, or it's stop breastfeeding, or wait and get, because I haven't pumped on time. Speaker 1:Mm-hmm (affirmative). So how ... What has the classroom environment been like for you, and navigating that? Regarding your teachers, fellow classmates, or even just the physical rooms at Portland State.

Participant 4:Hm. Let me think for a second. 
Speaker 1:Yeah, no problem.

Participant 4:I've had some difficulty with some teachers understanding what my needs are. I've had some difficulty with teachers understanding that I cannot write them an eloquent email, because it takes me three times as long, just with the vision impairment. But then, yeah, I'm not as good as some of the Speedy McSpeedy's blind people. I'm not that good at all the blind skills. Doesn't matter that it's been my whole life, I'm just still not as good as some people. I'm actually quite slow when it comes to computer stuff. Participant 4:I had a teacher that just ... she thought it was disrespectful that I didn't write her a nicely formatted email.

Speaker 1:Wow.

Participant 4:She's like, "We keep classroom agreements, and one of them is to be respectful, and I thought it was very disrespectful the way you've been sending me emails. I don't need to hear that you have all these problems." I'm like, "Well, look, I'm legally blind, and I have a baby, and I really needed some guidance on the last paper, and I was buying a house at the time. So, my time-wise was really short, and I have to stop every two hours and feed my baby. I don't have time to write you a nice email. There was no malice behind it, and I was trying to illustrate to you what was going on for me. So, I am really sorry."

Participant 4:She's like, "Well, can you keep our classroom agreements? Can you agree to that?" I was like, "Sure." I said yes, because she's my superior, but ultimately, I was walking out of the classroom like, "I'm switching classes right now." Speaker 1:Ah, yeah. Any- 
STUDY OF EQUITABLE ACADEMIA FOR STUDENTS WITH DISABILITIES

Participant 4:So, that just ... I mean, that's the kind of thing you get a professional every now and again that is not understanding.

Speaker 1:Yeah, that must be very difficult, especially when you're communicating what you need from them, and I'm assuming that..

Participant 4:I just wanted to talk on the phone.

Speaker 1:Yeah.

Participant 4: Like that's all I'm asking her was, "Can we talk on the phone for five minutes?" Because I can communicate a lot more in five minutes on the phone than I can in an email.

Speaker 1:Mm-hmm (affirmative). Now Catherine, I just want to verify with you, is it okay if we continue with the interview? I know it's a little bit longer than we had expected. Is that all right? Participant 4:Yeah, that's fine. How many questions more do you think you have? Speaker 1:Oh, just two more.

Participant 4:Okay, perfect.

Speaker 1:The last two are about your experience at the DRC.

Participant 4:Oh, okay, yeah. Oh, also classroom-wise, our classrooms in the social work school are all right for a blind person. I do think that it could be improved by just ... since we are so visual with the whiteboard, if they switched over to digital whiteboards instead, and you could actually get a live feed on a tablet, that would be a lot more helpful for visually impaired people, so they can engage visually in the class. Because it is a collaborative environment, it's not like someone's writing stuff up and lecturing on it, it's collaborative. 
STUDY OF EQUITABLE ACADEMIA FOR STUDENTS WITH DISABILITIES

Participant 4:So, that would be my suggestion, because it is very difficult to be

collaborative when you have no idea what they just wrote up there.

Speaker 1:Mm-hmm (affirmative). That sounds ... and honestly, that sounds like a great idea. So, why did you decide to register with the DRC?

Participant 4:Well, I think it ... that's a funny question, because it would seem like a no thought kind of thing went into that for me, and I just knew that I needed to get accommodations set up, and that that was part of the process. It says it in every single syllabus, but also before I ever saw a syllabus, I recognized that was going to be the case. Participant 4:With being a parent, I knew that I was going to have even more challenges. Just the breastfeeding accommodation, I would need to go through the DRC.

Speaker 1:Okay. So, what is one thing, or a few things, that you think the DRC could improve at?

Participant 4:I think it needs more inter-student services relationships. It would be really nice too if there was not a neoliberal attitude about independence, because I cannot be independent right now.

Speaker 1:Mm-hmm (affirmative).

Participant 4:I kind of need someone to nanny me, like, "Did you fully understand the process of note-taking?" Not like a ... Also, I can't go to one of their little lecture workshops about how to use services. They should just put it on YouTube or something, because I can't make that time. If they did things like entice me with free childcare, maybe, sure, it could possibly, maybe, make me go to one of those things. But I'm not going to pay to learn how to access the system better and make time for it. 
STUDY OF EQUITABLE ACADEMIA FOR STUDENTS WITH DISABILITIES

Participant 4:I don't mean that in any kind of negative like, "I'm not going to do it." No, it's more like, I just can't ... it doesn't push me over into the pro column, I'm still over in the cons column, you know?

Speaker 1:Yeah, definitely.

Participant 4:I'm like, "That's time and money." It would just be better if somebody was like, "Okay, so I just want to reiterate, if you don't understand how you have to, for instance, confirm your note-taker." I thought all I had to do was click a little thing and then it was done, but no, you have to go back and say, yes, no, and I do need it. I do need it. The second week of school, which is ridiculous, I would've appreciated somebody doing that.

Participant 4:Because also in graduate school we need note-takers the first week, because it's actual class the first week. We don't have class the last week, but we have actual class the first week. So, it's not really setup completely for graduate school, which is really frustrating. But, I mean, I still have the impression of it being a very nebulous set of services that I don't really understand how they all work.

Participant 4:That would be okay if it wasn't like the ... I think that they are on their way to not having that idea of the student is independent and driving this process. But, I really think there should be a way to be like, "Yes, I want a nanny. I would like you to shepard me through this, because I do not have the time, nor the mental space to figure it out." Speaker 1:Mm-hmm (affirmative).

Participant 4:I think it should be something that you're like, "I kind of need this. Oh, you told me that you offer me that." Then, if you really need it, they will make it happen. Not in every case, but just, you know, if you really need it, you know? I'm just saying. 
STUDY OF EQUITABLE ACADEMIA FOR STUDENTS WITH DISABILITIES

Speaker 1:Absolutely.

Participant 4:Okay, I'm saying [inaudible 00:15:54] a lot. Everybody would agree with me, but it's just so hard.

Speaker 1:Yeah, definitely. You know, I really appreciate you taking the time out of your day to speak with me. That's pretty much it for the questions that I have. Is there anything you want to say in the last few minutes?

Participant 4:I would say that the very compassionate councilor type relationship that people engage with at the DRC is very successful. I have been at other places where there is ... This is professional, it's professional type of compassion and connection. But that is much more successful than other schools I've gone to, where it's a very cold, mechanized, process.

Participant 4:So, I think Portland State should value their councilors very highly, and understand that the more opportunities that they can give students by say providing more money for staff that's giving more time for them to engage with students, even just calling and checking in on them, or writing an email just checking in on them. Because I mean, my first year, three year councilor through my program does that.

Participant 4:Those kinds of interactions go a long way to making sure everybody's on track, and doing well, but also encourages them. I think that psychological bolstering does a lot.

Speaker 1:Yeah. Well, thank you so much. I hope you have a great day, and I wish you the best in the rest of your studies.

Participant 4:You too, Mia. Congratulations on your thesis, I hope the rest goes well. Speaker 1:Thank you so much. Bye. 


\section{Participant 4:Bye.}

\section{Appendices 5}

\section{Venn diagram of themes in study}

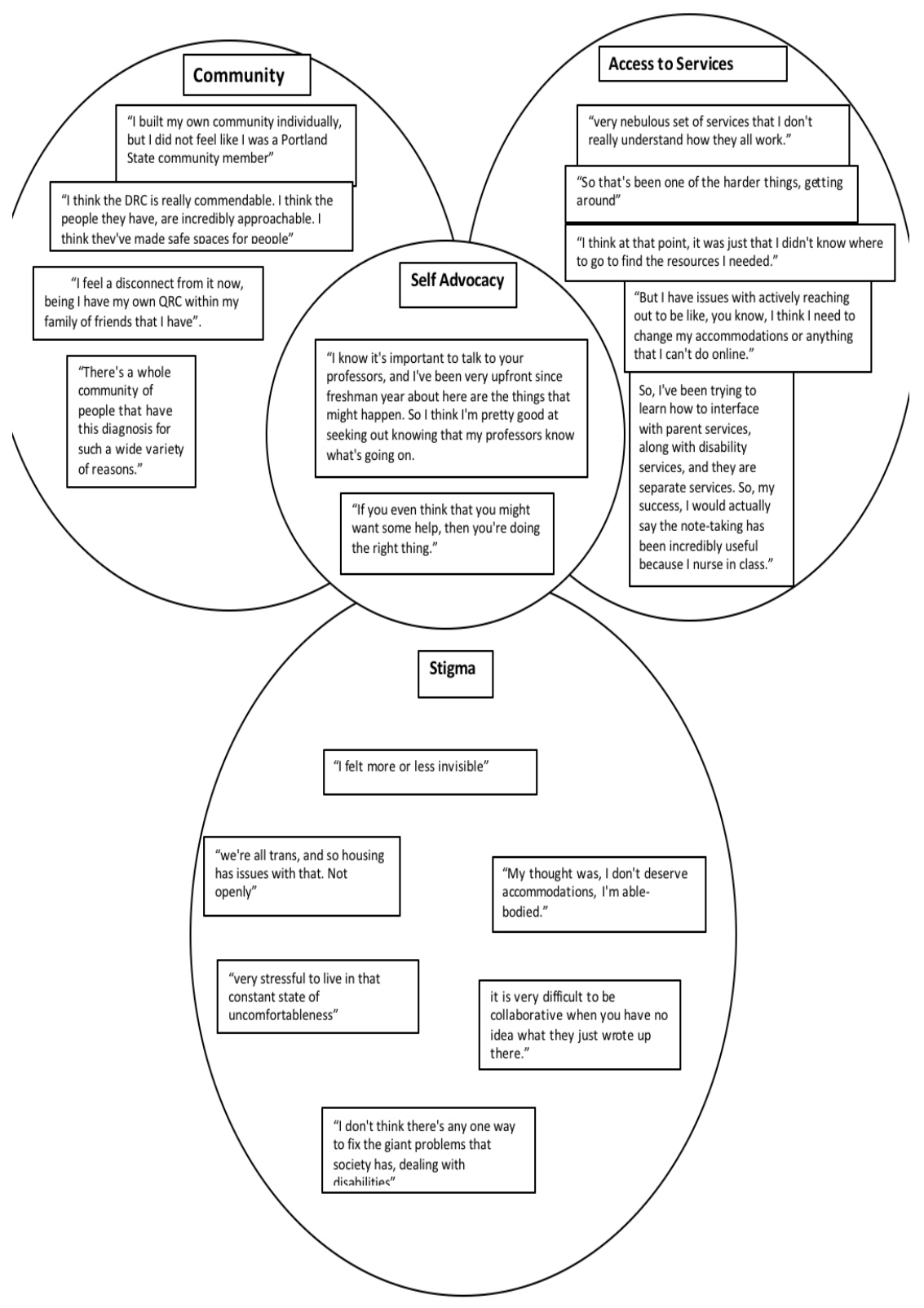

